\title{
Concentrations of Toxic Metals and Essential Minerals in the Mane Hair of Healthy Racing Horses and Their Relation to Age
}

\author{
Ryuji ASANO ${ }^{1)}$, Kazuyuki SUZUKI ${ }^{1)}$, Tomonari OTSUKA ${ }^{2)}$, Masao OTSUKA ${ }^{2)}$ and Hidetoshi SAKURAI ${ }^{3)}$ \\ ${ }^{1)}$ Department of Veterinary Medicine, College of Bioresource Sciences, Nihon University, 1866 Kameino, Fujisawa, Kanagawa 252-8510, \\ ${ }^{2)}$ Otsuka Animal Hospital, 2-2-34 Katsushima, Shinagawa, Tokyo 140-0012 and Department of Agricultural Chemistry, College of \\ Bioresource Sciences, Nihon University, 1866 Kameino, Fujisawa, Kanagawa 252-8510, Japan
}

(Received 27 November 2001/Accepted 11 March 2002)

abstract. Concentrations of trace elements (As, Al, $\mathrm{Pb}, \mathrm{Cd}, \mathrm{Hg}, \mathrm{Se}, \mathrm{Si}, \mathrm{P}, \mathrm{Na}, \mathrm{K}, \mathrm{Ca}, \mathrm{Mg}, \mathrm{Fe}, \mathrm{Cu}, \mathrm{Zn}, \mathrm{Mn}, \mathrm{Cr}, \mathrm{Ni}$ and $\mathrm{Mn}$ ) in the mane hair obtained from 9 female and 15 male healthy racing Thoroughbred horses aged 2-5 years were analyzed by the inductively coupled plasma atomic emission spectrometry (ICP-AES) method. No significant differences between the female and male horses were observ ed in the mean concentrations of those minerals. Significantly positive correlations with age were observed in $\mathrm{Cd}(\mathrm{r}=0.546, \mathrm{p}<0.01)$ and Mo $(r=0.733$, $p<0.001)$. Significantly negative correlations with age were observed in $\mathrm{Hg}(r=-0.726, p<0.001), \mathrm{Mn}(\mathrm{r}=-0.450, \mathrm{p}<0.05)$ and $\mathrm{Fe}(\mathrm{r}=-0.642, \mathrm{p}<0.01)$. This reference range of trace elements in the mane hair of racing horses should be used to assess disease and the nutritional status in equine practice.

KEY WORDS: equine, ICP-AES, trace element.

J. Vet. Med. Sci. 64(7): 607-610, 2002

The levels of trace elements in biological samples from a horse are used to assess diseases and metabolic disorders. For examples, spontaneous vascular mineralization in the brain of the horse has been shown to be associated with the imbalance of elements such as a large amount of Al and a small amount of $\mathrm{Na}$ [14]. Increased biological $\mathrm{Cu}$ levels induced equine motor neuron disease [8] and hypersensitivity to culicoides [12]. The levels of trace elements in biological samples from a horse are also used to assess the nutritional status. Management practices clearly influence the Fe state in young growing foals, and although not a frequent cause of anemia in the horse, an absolute deficit of body Fe occur in stabled horses fed fresh cut grass [1]. Ca absorption was unaffected by $\mathrm{Al}$ intake, but the horses were in negative $\mathrm{Ca}$ balance when fed a high aluminum diet due to greater urinary excretion of $\mathrm{Ca}$ [11]. Therefore the levels of some trace elements are related to animal systemic levels. Various specimens, such as blood [5-7, 13] or hair [2-4, 9], may be used to assess the trace element status in man and animals. The concentrations of trace elements are higher in hair than in other body organs and fluids, and sampling and storage of hair are easier than those of other biological materials [4].

The potential usefulness of hair analysis was established in the early $1960 \mathrm{~s}$, but the most significant development in the field of hair analysis has taken place over the past 10 years [2]. Considering the origin of the trace elements in hair, two main sources have to be distinguished as exogenous and endogenous. Exogenous quantities are those attached to the hair by the direct environmental contact after the hair has been formed. The exogenous concentrations of metals could be considered to easily removed by washing. Endogenous quantities of metals are those incorporated into the hair proteins during the short period of its formation, and the binding of endogenous trace elements in the hair struc- ture is assumed to be metabolically inert, irreversible, or quite firm [2].

The primary purpose of this study was to establish reference ranges of trace elements such as toxic metals (As, Al, $\mathrm{Pb}, \mathrm{Cd}$ and $\mathrm{Hg}$ ) and essential minerals (Se, Si, P, Na, K, Ca, $\mathrm{Mg}, \mathrm{Fe}, \mathrm{Cu}, \mathrm{Zn}, \mathrm{Mn}, \mathrm{Cr}, \mathrm{Ni}$ and $\mathrm{Mo}$ ) in the mane hair of healthy racing horses by means of inductively coupled plasma-atomic emission spectrometry (ICP-AES). Additional objectives include the relationships of mean concentrations of those trace elements to age and sex in the mane hair of healthy racing Thoroughbred horses.

Samples were obtained from 9 female and 15 male racing Thoroughbred horses aged 2-5 years. The horses were deemed healthy on the basis of physical examination. Hair specimens collected were a total $1.0 \mathrm{~g}$ of mane hair from the nape area nearest to the skin. The hair specimens were further cut and washed by the modified methods of the International Atomic Energy Agency (IAEA)[2,3,9]. The hair was first cut into $0.3 \mathrm{~cm}$ pieces and mixed to allow a representative subsampling of the hair specimen. After cutting, each sample was washed four times with a 1:200 vol/vol dilution of Triton X-100 (Sigma Chemical Co., MO, U.S.A.). Chyla and Zyrnicki [2] investigated the influence of various washing solutions on the concentrations of trace elements measured in hair of dogs, and indicated that Triton X-100 was found to be suitable to use for the removal of exogenous elements in multielemental hair analysis. The samples were then rinsed twice with isopropylalcohol and allowed to drain. This was followed by rinses with deionized water (18-M $\Omega$ ) and two more rinses with acetone, then allowed to drain [10]. Deionized water used during all pretreatments was prepared in an ultrapure water purification system (Milli-QII, Millipore, MA, U.S.A.). The samples were then dried on a hot plate (model HK-21, Yamato Science Co., Ltd., Tokyo) at $70^{\circ} \mathrm{C}$. Open-beaker digestion method for the 
Table 1. The reference ranges of concentrations of the toxic metals and essential minerals in the mane hair of healthy racing horses

\begin{tabular}{|c|c|c|c|c|c|c|c|c|}
\hline \multicolumn{3}{|c|}{ Elements } & \multicolumn{5}{|c|}{ Concentrations of elements ( $\mu \mathrm{g} / \mathrm{g}$ of hair) } & \\
\hline & & \multirow[b]{2}{*}{$\begin{array}{l}\text { Total } \\
(\mathrm{n}=24)\end{array}$} & \multicolumn{2}{|c|}{ Sex } & \multicolumn{4}{|c|}{ Age (years) } \\
\hline & & & $\begin{array}{c}\text { Female } \\
(\mathrm{n}=9)\end{array}$ & $\begin{array}{l}\text { Male } \\
(\mathrm{n}=15)\end{array}$ & $\begin{array}{c}2 \\
(\mathrm{n}=3)\end{array}$ & $\begin{array}{c}3 \\
(\mathrm{n}=8)\end{array}$ & $\begin{array}{c}4 \\
(n=7)\end{array}$ & $\begin{array}{c}5 \\
(\mathrm{n}=6)\end{array}$ \\
\hline \multirow{5}{*}{$\begin{array}{l}\text { Toxic } \\
\text { Metals }\end{array}$} & As & $1.16 \pm 0.44$ & $1.25 \pm 0.57$ & $1.12 \pm 0.36$ & $1.55 \pm 0.95$ & $0.98 \pm 0.05$ & $1.22 \pm 0.53$ & $1.11 \pm 0.17$ \\
\hline & $\mathrm{Al}$ & $64.5 \pm 77.0$ & $84.4 \pm 113.5$ & $61.4 \pm 50.4$ & $152.3 \pm 171.3$ & $67.1 \pm 70.6$ & $57.8 \pm 36.6$ & $25.1 \pm 19.2$ \\
\hline & $\mathrm{Pb}$ & $0.93 \pm 0.78$ & $1.24 \pm 1.28$ & $0.76 \pm 0.28$ & $0.71 \pm 0.02$ & $1.13 \pm 1.31$ & $0.92 \pm 0.36$ & $0.77 \pm 0.29$ \\
\hline & $\mathrm{Cd}$ & $0.12 \pm 0.12$ & $0.09 \pm 0.06$ & $0.15 \pm 0.13$ & $0.04 \pm 0.00$ & $0.11 \pm 0.14$ & $0.11 \pm 0.14$ & $0.20 \pm 0.06$ \\
\hline & $\mathrm{Hg}$ & $0.31 \pm 0.02$ & $0.34 \pm 0.23$ & $0.28 \pm 0.20$ & $0.49 \pm 0.16$ & $0.41 \pm 0.13$ & $0.35 \pm 0.12$ & $0.04 \pm 0.06$ \\
\hline \multirow{14}{*}{$\begin{array}{l}\text { Essential } \\
\text { Minerals }\end{array}$} & $\mathrm{Se}$ & $1.29 \pm 0.56$ & $1.40 \pm 0.83$ & $0.26 \pm 0.38$ & $1.00 \pm 0.00$ & $1.07 \pm 0.14$ & $1.78 \pm 0.85$ & $1.17 \pm 0.21$ \\
\hline & $\mathrm{Si}$ & $20.2 \pm 19.2$ & $17.8 \pm 11.9$ & $27.0 \pm 25.0$ & $8.9 \pm 14.2$ & $11.8 \pm 16.6$ & $12.8 \pm 18.0$ & $34.7 \pm 17.3$ \\
\hline & $\mathrm{P}$ & $324.9 \pm 132.8$ & $331.0 \pm 98.0$ & $346.0 \pm 162.0$ & $243.0 \pm 72.0$ & $310.0 \pm 62.0$ & $315.0 \pm 198.0$ & $398.0 \pm 125.0$ \\
\hline & $\mathrm{Na}$ & $582.0 \pm 476.3$ & $681.0 \pm 606.0$ & $458.0 \pm 358.0$ & $32.0 \pm 21.0$ & $836.0 \pm 562.0$ & $447.0 \pm 405.0$ & $676.0 \pm 287.0$ \\
\hline & $\mathrm{K}$ & $617.0 \pm 686.0$ & $870.0 \pm 904.0$ & $386.0 \pm 343.0$ & $90.8 \pm 28.9$ & $937.6 \pm 951.8$ & $436.5 \pm 383.6$ & $685.8 \pm 501.9$ \\
\hline & $\mathrm{Ca}$ & $1309.0 \pm 523.0$ & $1597.0 \pm 484.0$ & $1196.0 \pm 538.0$ & $994.7 \pm 291.2$ & $1650.8 \pm 473.1$ & $1148.3 \pm 492.3$ & $1199.8 \pm 567.1$ \\
\hline & $\mathrm{Mg}$ & $396.0 \pm 336.0$ & $548.0 \pm 520.0$ & $300.0 \pm 153.0$ & $245.7 \pm 134.4$ & $340.3 \pm 138.6$ & $348.0 \pm 161.3$ & $602.0 \pm 617.8$ \\
\hline & $\mathrm{Fe}$ & $69.0 \pm 83.0$ & $99.0 \pm 132.0$ & $60.0 \pm 44.0$ & $191.9 \pm 191.1$ & $69.9 \pm 47.0$ & $55.6 \pm 36.7$ & $22.4 \pm 17.5$ \\
\hline & $\mathrm{Cu}$ & $4.8 \pm 1.3$ & $5.0 \pm 1.4$ & $5.0 \pm 1.7$ & $4.7 \pm 0.8$ & $4.4 \pm 0.4$ & $4.3 \pm 1.8$ & $5.9 \pm 1.0$ \\
\hline & $\mathrm{Zn}$ & $86.0 \pm 24.0$ & $92.0 \pm 25.0$ & $88.0 \pm 31.0$ & $86.0 \pm 40.7$ & $81.6 \pm 7.2$ & $77.5 \pm 32.5$ & $101.7 \pm 14.9$ \\
\hline & $\mathrm{Mn}$ & $5.20 \pm 3.35$ & $4.86 \pm 2.73$ & $5.06 \pm 3.77$ & $9.63 \pm 2.71$ & $5.06 \pm 2.00$ & $3.62 \pm 2.25$ & $4.99 \pm 4.25$ \\
\hline & $\mathrm{Cr}$ & $0.22 \pm 0.16$ & $0.20 \pm 0.17$ & $0.23 \pm 0.15$ & $0.30 \pm 0.26$ & $0.20 \pm 0.14$ & $0.25 \pm 0.19$ & $0.16 \pm 0.07$ \\
\hline & $\mathrm{Ni}$ & $0.26 \pm 0.09$ & $0.23 \pm 0.07$ & $0.28 \pm 0.10$ & $0.28 \pm 0.07$ & $0.26 \pm 0.08$ & $0.27 \pm 0.10$ & $0.26 \pm 0.13$ \\
\hline & Mo & $0.55 \pm 0.65$ & $0.45 \pm 0.07$ & $0.67 \pm 0.71$ & $0.10 \pm 0.00$ & $0.15 \pm 0.13$ & $0.44 \pm 0.66$ & $1.44 \pm 0.25$ \\
\hline
\end{tabular}

Mean ages of female and male horses were $4.0 \pm 1.2$ and $3.3 \pm 1.3$ years old, respectively.

hair was used to prepare samples for analysis by ICP-AES, which resulted in a complete digestion. The digestion method used was simple: with the following inexpensive equipment [9]. Five hundred $\mathrm{mg}$ of each washed hair sample was accurately weighed into $10 \mathrm{~m} l$ quartz beakers, and then $2 \mathrm{~m} l$ of concentrated trace-metal grade nitric acid (Wako Pure Chemical Industries Ltd., Osaka) was added. The quartz beakers were sealed and placed at a room temperature for $24 \mathrm{hr}$. After the $24 \mathrm{hr}, 1 \mathrm{ml}$ of nitric acid was added to each beaker, and they were heated on a hot plate at $90^{\circ} \mathrm{C}$ for $3 \mathrm{hr}$. After cooling, $1 \mathrm{ml}$ of hydrogen peroxide was added, and then the solution was heated on a hot plate at $100^{\circ} \mathrm{C}$ for $1 \mathrm{hr}$. After the wet combination, each sample was diluted with nitric acid to reach a final volume of $10 \mathrm{ml}$. Duplicate digestions of each sample were prepared and measured. The concentrations of the trace elements were determined by ICP-AES (SPS1700R, Seiko Instruments Inc., Tokyo) with argon gas as the carrier gas.

The differences between female and male in the mean concentrations of elements were compared by unpaired Student's or Welch's $t$-test after distribution was analyzed by $F$-test. The relationship between the concentration of each element and age was evaluated by the Spearman rank correlation test. The significance level was $\mathrm{p}<0.05$.

The reference ranges for the racing horses established in this study are summarized in Table 1 . No significant differences between the female and male horses in the mean concentrations of those minerals were observed. Relationships between age and the concentrations of some toxic metals such as $\mathrm{Cd}$ and $\mathrm{Hg}$ are shown in Fig. 1. A significantly positive correlation with age was observed in the $\mathrm{Cd}$ concentra- tion $(\mathrm{r}=0.546, \mathrm{p}<0.01)$. In contrast, a significantly negative correlation with age was observed in the $\mathrm{Hg}$ concentration $(\mathrm{r}=-0.726, \mathrm{p}<0.001)$. Relationships between age and the concentrations of some essential minerals such as Mn, Mo and Fe are shown in Fig. 2. Significantly negative correlations with age were observed in $\mathrm{Mn}(\mathrm{r}=-0.450, \mathrm{p}<0.05)$ and $\mathrm{Fe}(\mathrm{r}=-0.642, \mathrm{p}<0.01)$ concentrations. There was a close positive correlation between age and $\mathrm{Mo}(\mathrm{r}=0.733$, $\mathrm{p}<0.001)$ concentration. To conclude, in the present study, the concentrations of the elements measured in the racing horse's mane hair were similar to those found for human $[4,9]$ and dog hair [2]. Only As and $\mathrm{Pb}$ content was slightly lower and the $\mathrm{P}, \mathrm{K}$ and $\mathrm{Mg}$ concentration was higher in horse's hair than in human hairs $[2,4,9]$.

The levels of trace elements in mane hair of horses can be used to assess diseases, metabolic disorders and nutritional status, because sampling and storage of hair are easier than those of other biological materials [4]. Therefore, this reference range of trace elements in mane hair of racing horses should be used to assess disease and nutritional status in equine practice.

\section{REFERENCES}

1. Brommer, H. and van Oldruitenborgh-Oosterbaan, M. M. 2001. J. Vet. Intern Med. 15: 482-485.

2. Chyla, M. A. and Zyrnicki, W. 2000. Biol. Trace Element Res. 75: 187-194.

3. Dever, M. and Bresee, R. R. 1990. J. Invest Dermatol. 94: 322326.

4. Feng, Q., Suzuki, Y. and Hisashige, A. 1997. Biol. Trace Element Res. 59: 75-86. 

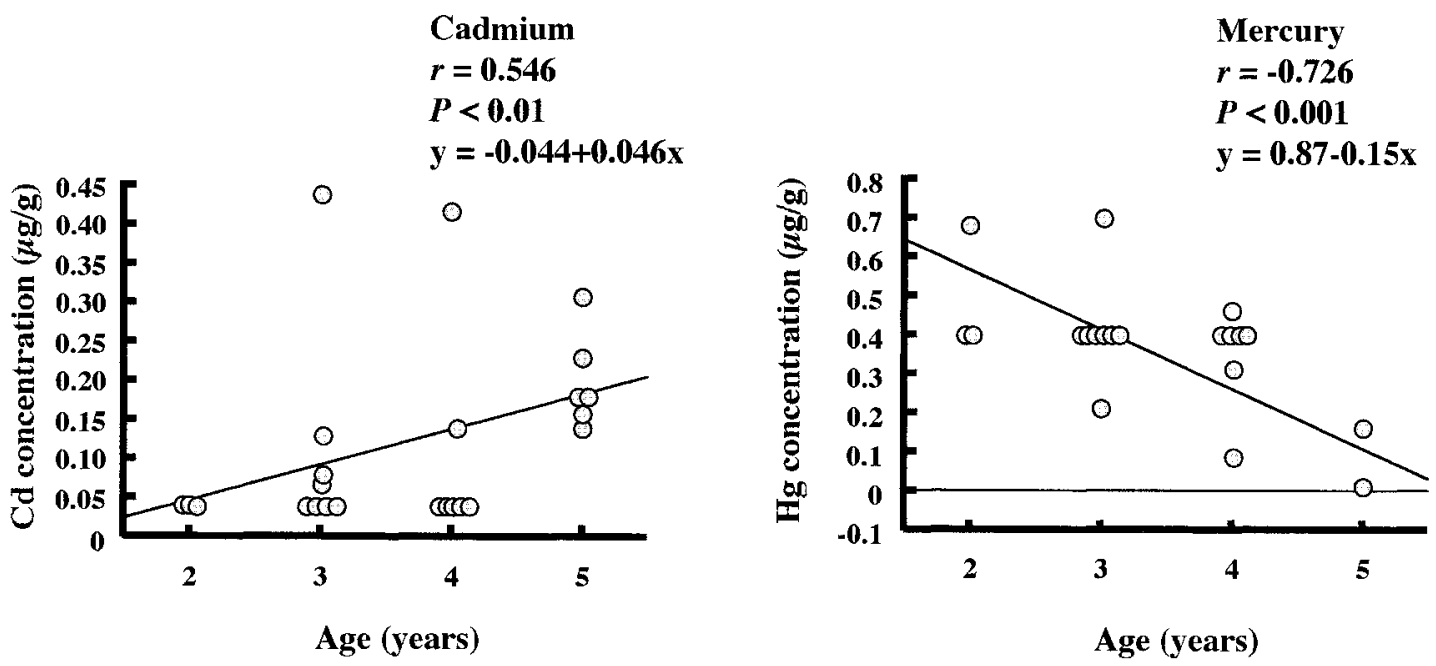

Fig. 1. Relationships between age and concentrations of some toxic metals such as Cadmium (Cd), and Mercury (Hg) in the mane hair of healthy racing Thoroughbred horses. The solid line is the liner regression line.
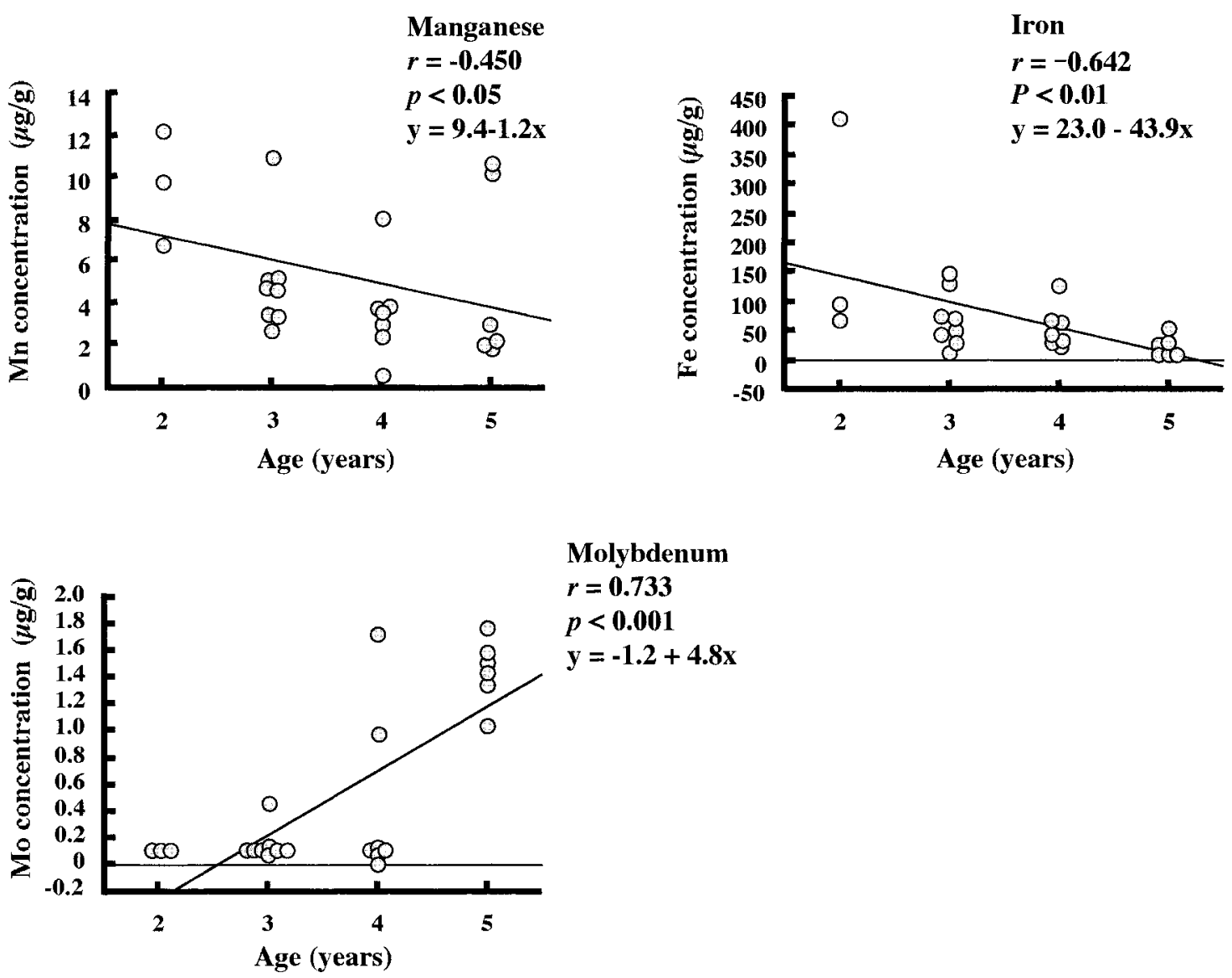

Fig. 2. Relationships between age and concentrations of essential minerals such as Manganese (Mn), Iron (Fe) and Molybdenum (Mo) in the mane hair of healthy racing Thoroughbred horses. The solid line is the liner regression line. 
5. Forrer, R., Gautschi, K. and Lutz, H. 2001. Biol. Trace Element Res. 80: 77-93.

6. Forrer, R., Wenker, C., Gautschi, K. and Lutz, H. 2001. Biol. Trace Element Res. 81: 47-62.

7. Melton, L. A., Tracy, M. L. and Moller, G. 1990. Clin. Chem. 36: $247-250$.

8. Polack, E. M., King, J. M., Cummings, J. F., Mohammed, H. O., Birch, M. and Cronin, T. 2000. Am. J. Vet. Res. 61: 609611.

9. Puchyr, R. F., Bass, D. A., Gajewski, R., Calvin, M., Marquardt, W., Urek, K., Druyan, M. E. and Quig, D. 1998. Biol. Trace Element Res. 62: 167-182.
10. Rader, J. I., Wolnik, K. A., Gaston, C. M., Celesk, E. M., Rwwlwe, J. T., Fox, M. R. S. and Fricke, F. L. 1984. J. Nutr. 114: $1946-1954$.

11. Schryver, H. F., Millis, D. L., Soderholm, L. V., Williams, J. and Hintz, H. F. 1986. Conell Vet. 76: 354-360.

12. Stark, G., Schneider, B. and Gemeiner, M. 2001. Equine Vet. J. 33: 506-509.

13. Vanhoe, H., Vandecasteele, C., Versieck, J. and Dams, R. 1989. Anal. Chem. 61: 1851-1857.

14. Yanai, T., Masegi, T., Ishikawa, K., Sakai, H., Iwasaki, T., Moritomo, Y. and Goto, N. 1996. J. Vet. Med. Sci. 58: 35-40. 